\title{
BMJ Open Patients' estimations of the importance of preventive health services: a nationwide, population-based cross-sectional study in Portugal
}

\author{
Luísa Sá, ${ }^{1,2}$ Orquídea Ribeiro, ${ }^{3}$ Luís Filipe Azevedo, ${ }^{3}$ Luciana Couto, ${ }^{1}$ \\ Altamiro Costa-Pereira, ${ }^{3}$ Alberto Hespanhol, ${ }^{1,3}$ Paulo Santos, ${ }^{1,3}$ Carlos Martins ${ }^{1,3}$
}

To cite: Sá L, Ribeiro 0, Azevedo LF, et al. Patients' estimations of the importance of preventive health services: a nationwide, populationbased cross-sectional study in Portugal. BMJ Open 2016;6:e011755. doi:10.1136/bmjopen-2016011755

- Prepublication history for this paper is available online. To view these files please visit the journal online (http://dx.doi.org/10.1136/ bmjopen-2016-011755).

Received 2 March 2016 Revised 16 May 2016 Accepted 3 August 2016

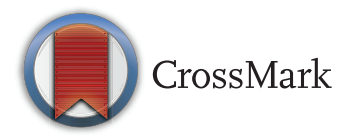

${ }^{1}$ Family Medicine Unit, Social Sciences and Health Department, Faculty of Medicine, University of Porto, Porto, Portugal

${ }^{2}$ Family Health Unit Nova Via, Porto, Portugal

${ }^{3}$ Faculty of Medicine, Centre for Research in Health Technologies and Information Systems (CINTESIS) and Information Sciences and Decision on Health Department (CIDES), University of Porto, Porto, Portugal

Correspondence to

Dr Luísa Sá;

luisa.de.sa@gmail.com

\section{ABSTRACT}

Objectives: To determine, in the context of primary care preventive health services, the level of importance that Portuguese patients attribute to different preventive activities.

Design: Cross-sectional study.

Setting: Primary Healthcare, Portugal.

Participants: 1000 Portuguese adults selected by a stratified cluster sampling design were invited to participate in a computer-assisted telephone survey. Persons with a cognitive or physical disability that hampered the ability to complete a telephone interview and being a nursing home resident or resident in any other type of collective dwelling were excluded.

Outcomes: Mean level of importance assigned to 20 different medical preventive activities, using a scale of 1-10, with 1 corresponding to 'no importance for you and your health' and 10 indicating 'very important'.

Results: The mean level of importance assigned to medical preventive activity was $7.70(95 \% \mathrm{Cl} 7.60$ to 7.80). Routine blood and urine tests were considered the most important, with an estimated mean of 9.15 (95\% Cl 9.07 to 9.24 ), followed by female-specific interventions (Pap smear, mammography and gynaecological and breast ultrasounds), with mean importance ranging from $8.45(95 \% \mathrm{Cl} 8.23$ to 8.63$)$ for mammography to $8.56(95 \% \mathrm{Cl} 8.36$ to 8.76$)$ for Pap smear. Advice regarding alcohol consumption $(6.18 ; 95 \% \mathrm{Cl} 5.96$ to 6.39$)$ and tobacco consumption (5.99; 95\% Cl 5.75 to 6.23) were considered much less important.

Conclusions: Our results reveal that Portuguese patients overestimate the importance of preventive medical activities, tend to give more importance to diagnostic and laboratory tests than to lifestyle measures, do not discriminate tests that are important and evidence-based, and seem not be aware of the individualisation of risk. Family physicians should be aware of these optimistic expectations, because these can influence the doctorpatient relationship when discussing these interventions and incorporating personalised risk.

\section{Strengths and limitations of this study}

- A population based cross-sectional study with a representative sample of 1000 Portuguese adults and 20 medical preventive activities considered.

- To the best of our knowledge, this is the first study about perceived importance attributed by patients to different preventive activities.

- This study gives additional evidence that Portuguese patients overestimate the importance of preventive medical activities, many of them are not evidence-based.

- The response rate of $55 \%$ and the quotasampling scheme may be considered as limitations.

\section{INTRODUCTION}

The growing importance attributed to clinical prevention encourages family physicians (FPs) to recommend screening and preventive interventions to their patients, who were also encouraged to participate in a range of national screenings. ${ }^{1}$ Despite the benefits of some of these interventions, individual assessments of the potential benefits and risks was not taken into account, and many of these medical tests have been prescribed to people who are healthy or have some risk factors. ${ }^{2}$ Advances in technology, the increasing number of medical tests available for doctors and patients, the cultural belief that more is always better and some disease-mongering strategies have led preventive medicine to a point where the probability of causing more harm than good is raising great concern. ${ }^{2-5}$ The excessive and unnecessary prescription of medical tests has important economic and ethical implications in current clinical practice. $^{256}$

Patients tend to overestimate the benefits achieved by screening and preventive treatments; ${ }^{1}$ 7-9 patients also tend to undergo 
some tests, for example, cancer screening tests, more often and at younger ages than the scientific evidence recommends. $^{2} 10$ Perhaps this happens because of increased social expectations to have a long and healthy life and patients and physicians are inundated with advice on how to do so. ${ }^{11}$

In Portugal the vast majority of the adult population considers a great number of medical tests necessary on a nearly annual basis, and most of the population indicate that they receive those tests. ${ }^{2}$ The same study also shows that patients' perceptions of required medical testing are far from what the scientific evidence recommends. Portuguese patients do not show a capacity for discriminating between medical tests that are performed on evidence-based recommendations and those that are not. $^{2}$

Many strategies are intended to improve the quality of medical test prescriptions but are based only on the doctor's actions, ignoring both the evolution of the medical consultation into a shared decision-making process $^{12}$ and the patient's expectations and beliefs. ${ }^{13}$

We believe that the development of educational interventions aiming to inform populations about the real impact and adequacy of certain healthcare services is crucial to promote the implementation of preventive services that may positively impact each patient's health. ${ }^{2}$ In this context, it is vital to understand how patients assess the value of medical tests.

The aim of this study was to determine, in the context of primary care preventive health services, the level of importance that Portuguese patients attribute to different preventive activities.

\section{MATERIALS AND METHODS}

\section{Study design}

A nationwide cross-sectional study was conducted, using a representative sample of Portuguese adults from the general population. Computer-assisted telephone interviews (CATIs) were used for data collection.

\section{Participant selection criteria}

The defined target population was Portuguese adults from the general population, and the available population included adults living in Portuguese households with a landline telephone (sampling frame). Eligible adults were aged 18 years and older and lived in a household (private dwelling) with a landline telephone. The exclusion criteria included having a cognitive or physical disability that hampered the ability to complete a telephone interview, being a nursing home resident or resident in any other type of collective dwelling and refusing to give informed consent for study participation.

\section{Survey sampling methods}

To obtain a representative sample of the Portuguese adults from the general population, a stratified cluster sampling design was used. First, all counties (geographical subdivisions of the Portuguese regions) were used as natural strata. In each county, a random sample of households with landline telephone numbers was selected with a probability proportional to the county's population size, as estimated by the national census. Next, one eligible resident was randomly selected in each household based on the birth date (last birthday before the call in the household was selected). Target quotas were set for age and sex strata in each geographical region, to account for the likelihood of being available at home for the interview and to correct the common over-representation of women and respondents from older age groups in telephone surveys. ${ }^{14-16}$

A comprehensive set of measures were implemented to prevent non-response and non-response bias. These included: (1) appropriate selection and specific training of interviewers; (2) an introductory presentation as the initial part of household contacts, specifically aimed at capturing participants' attention, obtaining their informed consent and facilitating participation; and (3) standard operational procedures for contacts and callbacks in case of failed contacts systematically including eight attempts on different days and at different times of the day. Additionally, to correct for sample imbalances and partially adjust prevalence estimates for selection bias, a set of weighting procedures were implemented. ${ }^{14-16}$ Two types of weights were used: (1) weights adapted to the sampling design (stratification and clustering), adjusting for different probabilities of selection among respondents and (2) post-stratification weights, taking into account population distributions by geographical region of residence, gender and 5-year age categories, based on the Portuguese National Census. ${ }^{17}$

\section{Quality control}

The interviewers were experienced and adequately trained and prepared for the application of the study questionnaire. A pilot run of 100 interviews was performed to assess the time needed for questionnaire completion, language and comprehension issues. A second pilot run was performed during the first 50 interviews. All interviews were supervised by a data collection supervisor; at least $20 \%$ of the interviews were randomly supervised by a study coordinator.

\section{Sample size}

The sample size was determined to estimate proportions with an expected margin of error of $4 \%$ (assuming a design effect of 1.5) and an intended confidence level (CI) of $95 \%$. Based on these assumptions, a sample of at least 1000 adults from the general population was required.

\section{Instruments and methods for data collection}

Data collection was performed from 16 February 2011 to 11 May 2011, using CATIs. A structured questionnaire containing four sections was used: (1) an introductory 
section that presented the study's aims and motivation; (2) a section that contained questions about the health status of the interviewees; (3) the main research section; and (4) a sociodemographic data collection section.

The main research section had two major parts. The first part asked about the medical tests patients deemed necessary and how often (the results of which are already published ${ }^{2}$ ). The second part asked, "What level of importance do you attribute to each of the following medical activities on a scale of 1 to 10 , with 1 corresponding to 'no importance for you and your health' and 10 indicating "very important'." This section included 20 medical interventions: blood test for cholesterol levels; counselling on weight; blood pressure evaluation; blood test for fasting glucose levels; smoking habits; faecal occult blood test (FOBT); chest X-ray; tetanus vaccine; routine blood and urine tests ('general analysis' is a popular expression in Portuguese in periodic health examinations or routine health checks and usually includes urinalysis, blood tests for complete blood count, glucose, total and high-density lipoprotein cholesterol, triglycerides, hepatic enzymes and creatine), ${ }^{2}$ advice on healthy eating; alcohol consumption habits; total colonoscopy; thyroid ultrasound; abdominal ultrasound; the male-specific interventions of prostate ultrasound scan and prostate-specific antigen test; and the female-specific interventions of mammography, breast ultrasound scan, gynaecological ultrasound scan, and Pap smear. In this article we report only about the levels of importance attributed to each test.

The interviewers were trained to clarify the meaning of each medical test to ensure that participants correctly understood all of the questions.

\section{Statistical analysis}

Statistical analysis was performed using the Statistical Package for the Social Sciences, V.19.0 for Windows (SPSS). All the presented prevalence estimates were calculated, after accounting for the sampling design and the appropriate weights described above, using the Complex Samples module of SPSS V.19.0. Point estimates are presented for all prevalence estimates. Point estimates and 95\% CI are presented for all mean estimates.

Descriptive statistics are presented as absolute frequency (number) and relative frequency (percentage) for categorical variables and as the mean for continuous variables. When testing hypotheses regarding continuous variables, parametric tests (Student's t-test and one-way analysis of variance) were used, accounting for normality assumptions and the number of groups compared.

Whenever statistical hypothesis testing was used, a significance level of $\alpha=5 \%$ was considered.

\section{Ethical considerations}

Participants provided their verbal informed consent at the beginning of the telephone interview. Written consent was not obtained because interviews were conducted by telephone, without the physical presence of the participants. Participants were informed about the estimated duration of the interview and voluntary participation was emphasised; they were notified that they could interrupt their participation at any moment of the interview. The interviews were not recorded and participants did not receive any kind of compensation. As a measure to standardise the process of obtaining informed consent, interviewers were specifically trained and required to read a standardised text and the interview began only after the patient's consent was received. The procedure of obtaining of consent was approved by the São João Health Centre Medical Ethics Committee.

\section{RESULTS}

From a total of 2945 randomly selected households, 1804 households had eligible individuals. From the total number of households with eligible individuals, 804 of the selected individuals refused to participate. We obtained 1000 valid interviews, corresponding to a response rate of $55 \%$. The mean duration of the interview was $18 \mathrm{~min}$. Respondents were between 18 and 97 years old; 520 were women and 480 were men. Table 1 presents the sample's demographic characteristics.

Table 1 shows that $58.9 \%$ of the respondents considered themselves to have a good-to-excellent health status. The self-reported prevalence in our sample indicated $25.0 \%$ for hypertension, $24.3 \%$ for hypercholesterolaemia, $6.6 \%$ for diabetes, $10.4 \%$ for heart problems, $9.6 \%$ for asthma and/or chronic obstructive pulmonary disease (COPD), 13.6\% for depression and 3.0\% for cancer.

The mean level of importance assigned to different medical preventive activities was 7.70 (table 2). The medical activity that patients considered most important was routine blood and urine tests, with a mean importance of 9.15; questions regarding alcohol consumption (6.18) and tobacco consumption (5.99) were considered the least important.

For female-specific interventions (Pap smear, mammography and gynaecological and breast ultrasound scan) the attributed level of importance ranged from 8.45 to 8.56 (table 2). Similar estimates of importance were given for the Pap smear and gynaecological ultrasound scan (8.56 vs 8.47 ) and for breast ultrasound scan and mammography (8.46 vs 8.45 ). In contrast, certain male-specific interventions were considered less important, that is, 7.72 and 7.73 for the evaluation of prostratespecific antigen (PSA) and prostate ultrasound scan, respectively.

Regarding colorectal cancer screening, the level of importance attributed to the FOBT was 7.40 and for total colonoscopy was 7.17 (table 2). Colorectal cancer screening was considered less important than prostate cancer screening in our sample.

Cardiovascular risk factor screenings (cholesterol evaluation (8.43), evaluation of glucose (8.24) and 
Table 1 Study sample demographic characteristics and self-perceived health status, medical conditions and risk factors

\begin{tabular}{|c|c|c|}
\hline & $\begin{array}{l}\text { Percentage of } \\
\text { respondents }\end{array}$ & $\begin{array}{l}\text { Unweighted } \\
\text { count }\end{array}$ \\
\hline \multicolumn{3}{|c|}{ Age (years) (Mean: 45; Range: 18-97) } \\
\hline From 18 to 29 & 26.7 & 233 \\
\hline From 30 to 39 & 17.6 & 184 \\
\hline From 40 to 49 & 16.4 & 169 \\
\hline From 50 to 59 & 14.1 & 145 \\
\hline From 60 to 69 & 12.6 & 131 \\
\hline From 70 to 79 & 9.2 & 96 \\
\hline 80 or older & 3.4 & 42 \\
\hline \multicolumn{3}{|l|}{ Gender } \\
\hline Male & 47.8 & 480 \\
\hline Female & 52.2 & 520 \\
\hline \multicolumn{3}{|c|}{ Geographic distribution (NUTS II) } \\
\hline North & 35.6 & 348 \\
\hline Center & 23.3 & 230 \\
\hline Lisbon & 26.4 & 262 \\
\hline Alentejo & 7.8 & 78 \\
\hline Algarve & 3.6 & 38 \\
\hline Madeira & 1.7 & 22 \\
\hline Azores & 1.6 & 22 \\
\hline \multicolumn{3}{|l|}{ Marital status } \\
\hline Single & 34.5 & 321 \\
\hline Married & 56.0 & 560 \\
\hline $\begin{array}{l}\text { Married but legally } \\
\text { separated }\end{array}$ & 0.8 & 8 \\
\hline Divorced & 2.7 & 31 \\
\hline Widowed & 6.1 & 77 \\
\hline \multicolumn{3}{|c|}{ Highest level of education completed } \\
\hline None & 2.8 & 35 \\
\hline $\begin{array}{l}\text { Basic, } 4 \text { years of } \\
\text { education }\end{array}$ & 23.7 & 250 \\
\hline $\begin{array}{l}\text { Basic, } 6 \text { years of } \\
\text { education }\end{array}$ & 7.0 & 72 \\
\hline $\begin{array}{l}\text { Basic, } 9 \text { years of } \\
\text { education }\end{array}$ & 17.9 & 171 \\
\hline $\begin{array}{l}\text { Secondary, } 12 \text { years } \\
\text { of education }\end{array}$ & 23.4 & 220 \\
\hline $\begin{array}{l}\text { Postsecondary } \\
\text { education } \\
\text { (professional } \\
\text { certificates) }\end{array}$ & 3.7 & 33 \\
\hline $\begin{array}{l}\text { Higher Education, } \\
\text { Bachelors }\end{array}$ & 2.1 & 21 \\
\hline $\begin{array}{l}\text { Higher Education, } \\
\text { Graduation }\end{array}$ & 16.6 & 167 \\
\hline $\begin{array}{l}\text { Higher Education, } \\
\text { Masters }\end{array}$ & 2.1 & 23 \\
\hline $\begin{array}{l}\text { Higher Education, } \\
\text { PhD }\end{array}$ & 0.6 & 6 \\
\hline \multicolumn{3}{|l|}{ Professional occupation } \\
\hline Has a profession & 53.3 & 534 \\
\hline Student & 11.7 & 96 \\
\hline Homemaker & 7.0 & 74 \\
\hline Retired & 21.8 & 234 \\
\hline Unemployed & 6.3 & 60 \\
\hline \multicolumn{3}{|l|}{ Residence location } \\
\hline
\end{tabular}

Table 1 Continued

\begin{tabular}{|c|c|c|}
\hline & $\begin{array}{l}\text { Percentage of } \\
\text { respondents }\end{array}$ & $\begin{array}{l}\text { Unweighted } \\
\text { count }\end{array}$ \\
\hline Urban & 55.3 & 559 \\
\hline Rural & 44.7 & 441 \\
\hline \multicolumn{3}{|c|}{ Health status (In general, would you say your health is:) } \\
\hline Excellent & 10.9 & 107 \\
\hline Very good & 15.3 & 139 \\
\hline Good & 32.7 & 326 \\
\hline Fair & 30.4 & 314 \\
\hline Poor & 10.8 & 114 \\
\hline \multicolumn{3}{|c|}{ Medical conditions and risk factors } \\
\hline Hypertension & 25.0 & 246 \\
\hline Elevated cholesterol & 24.3 & 270 \\
\hline Diabetes & 6.6 & 76 \\
\hline Heart problems & 10.4 & 109 \\
\hline Osteomuscular pain & 58.6 & 585 \\
\hline Asthma and/or COPD & 9.6 & 101 \\
\hline $\begin{array}{l}\text { Gastritis or peptic } \\
\text { ulcer disease }\end{array}$ & 11.2 & 122 \\
\hline Anxiety & 37.9 & 378 \\
\hline Depression & 13.6 & 141 \\
\hline Overweight or obesity & 26.0 & 260 \\
\hline Smoker & 17.3 & 183 \\
\hline Cancer & 3.0 & 34 \\
\hline $\begin{array}{l}\text { I am healthy, I do not } \\
\text { have any disease }\end{array}$ & 15.9 & 158 \\
\hline
\end{tabular}

blood pressure evaluation (8.17)) were considered very important.

Lifestyle measures (advice regarding healthy eating, weight and alcohol and tobacco consumption) were considered less important than other tests, with scores ranging from 5.99 to 7.91 (table 2). Advice regarding alcohol and tobacco consumption were considered the least important (6.18 and 5.99, respectively).

In table 3, for each specific medical activity, we compared the respondents with declared conditions or risk factors that would justify the importance of that medical test with the respondents without conditions or risk factors.

Comparing the data of patients with and patients without risk factors, we found similar results (table 3) except for blood pressure evaluation (7.44 vs 8.33, $\mathrm{p}<0.001)$ and glucose evaluation $(7.70$ vs $8.40, \mathrm{p}<0.001)$; these were significantly different between groups. Lung X-ray $(p=0,070)$, abdominal ultrasound scan $(p=0,942)$ and thyroid ultrasound scan $(p=0,882)$ were equally important to both groups.

Analysing only the respondents without conditions or risk factors, we verified that the levels of importance attributed to each of the evaluated tests were $>6.84$ and the results were quite similar to the global group analysis (tables 2 and 3).

Figure 1 shows the associations between demographic factors and the importance attributed to different 
Table 2 Mean level of importance that individuals attributed to medical activities, on a scale of 1-10; 1 corresponds to 'no importance' and 10 to 'very important'

\begin{tabular}{lllll}
\hline & & & $95 \% \mathbf{C l}$ & \\
\cline { 4 - 5 } Health services & $\mathbf{n}^{*}$ & Mean estimate & Lower & Upper \\
\hline Routine blood and urine tests & 988 & 9.15 & 9.07 & 9.24 \\
Pap smear & 495 & 8.56 & 8.36 & 8.76 \\
Gynaecological ultrasound scan & 500 & 8.47 & 8.26 & 8.68 \\
Breast ultrasound & 506 & 8.46 & 8.25 & 8.67 \\
Mammography & 505 & 8.45 & 8.31 & 8.66 \\
Cholesterol evaluation & 987 & 8.43 & 8.16 & 8.44 \\
Tetanus vaccine & 970 & 8.29 & 8.12 & 8.37 \\
Evaluation of glucose & 989 & 8.24 & 8.04 & 8.29 \\
Blood pressure evaluation & 990 & 8.17 & 7.77 & 8.06 \\
Health eating advice & 982 & 7.91 & 7.51 & 7.94 \\
Evaluation of PSA & 476 & 7.73 & 7.51 & 7.94 \\
Prostate ultrasound scan & 476 & 7.72 & 7.39 & 7.68 \\
Lung X-ray & 971 & 7.53 & 7.23 & 7.56 \\
FOBT & 954 & 7.40 & 7.21 & 7.52 \\
Abdominal ultrasound scan & 970 & 7.37 & 6.98 & 7.36 \\
Weight advice & 979 & 7.21 & 6.66 & 7.35 \\
Total colonoscopy & 937 & 7.17 & 5.96 & 7.02 \\
Thyroid ultrasound scan & 940 & 6.84 & 5.75 & 6.39 \\
Alcohol consumption & 941 & 6.18 & 7.60 & 7.83 \\
Smoking habits & 889 & 5.99 & & \\
Importance grade average & 993 & 7.70 & & \\
\hline
\end{tabular}

${ }^{*} n=1000$, but there were 'no answer' results.

FOBT, faecal occult blood test; PSA, prostate-specific antigen.

Table 3 Mean level of importance that individuals without risk factors* versus individuals with risk factors attribute to medical activities, on a scale of $1-10 ; 1$ corresponds to 'no importance' and 10 to 'very important'

\begin{tabular}{|c|c|c|c|c|c|c|c|c|c|}
\hline \multirow[b]{3}{*}{ Health services } & \multicolumn{4}{|c|}{ Individuals without risk factors* } & \multicolumn{4}{|c|}{ Individuals with risk factors } & \multirow[b]{3}{*}{ p Value } \\
\hline & \multirow[b]{2}{*}{$\mathbf{n}$} & \multirow[b]{2}{*}{ Mean estimate } & \multicolumn{2}{|c|}{$95 \% \mathrm{Cl}$} & \multirow[b]{2}{*}{$\mathbf{n}$} & \multirow[b]{2}{*}{ Mean estimate } & \multicolumn{2}{|l|}{$95 \% \mathrm{Cl}$} & \\
\hline & & & Lower & Upper & & & Lower & Upper & \\
\hline Pap smear & 471 & 8.57 & 8.36 & 8.78 & 24 & 8.27 & 7.62 & 8.92 & 0.385 \\
\hline Gynaecological ultrasound scan & 404 & 8.49 & 8.25 & 8.72 & 95 & 8.39 & 7.91 & 8.88 & 0.738 \\
\hline Mammography & 428 & 8.47 & 8.24 & 8.69 & 76 & 8.33 & 7.70 & 8.96 & 0.684 \\
\hline Breast ultrasound scan & 428 & 8.46 & 8.24 & 8.69 & 77 & 8.44 & 7.84 & 9.04 & 0.939 \\
\hline Cholesterol evaluation & 762 & 8.23 & 7.98 & 8.49 & 217 & 8.49 & 8.36 & 8.61 & 0.083 \\
\hline Evaluation of blood pressure & 266 & 7.74 & 7.50 & 7.98 & 715 & 8.33 & 8.19 & 8.48 & $<0.001$ \\
\hline Evaluation of glucose & 199 & 7.70 & 7.40 & 8.00 & 781 & 8.40 & 8.26 & 8.54 & $<0.001$ \\
\hline Prostate ultrasound scan & 459 & 7.69 & 7.47 & 7.91 & 13 & 8.34 & 7.38 & 9.31 & 0.196 \\
\hline Evaluation of PSA & 459 & 7.68 & 7.46 & 7.91 & 13 & 8.56 & 7.63 & 9.49 & 0.075 \\
\hline Lung X-ray & 825 & 7.48 & 7.32 & 7.63 & 141 & 7.88 & 7.47 & 8.30 & 0.070 \\
\hline FOBT & 867 & 7.37 & 7.20 & 7.55 & 82 & 7.48 & $6 . c$ & 8.0 & 0.721 \\
\hline Abdominal ultrasound scan & 923 & 7.36 & 7.20 & 7.53 & 41 & 7.39 & 6.65 & 8.14 & 0.942 \\
\hline Thyroid ultrasound scan & 962 & 6.84 & 6.66 & 7.02 & 9 & 6.74 & 5.36 & 8.11 & 0.882 \\
\hline \multicolumn{10}{|c|}{$\begin{array}{l}\text { FOBT, faecal occult blood test; PSA, prostate-specific antigen. } \\
\text { "For cholesterol evaluation, patients with high cholesterol, diabetes, heart problems, smoking habits, hypertension, obesity (BMI } \geq 30) \text {, or a } \\
\text { family history of heart problems were excluded. For evaluation of blood pressure, patients with diabetes, heart problems, obesity (BMI } \geq 30 \text { ), } \\
\text { smoking habits, hypertension, or a family history of heart problems were excluded. For evaluation of glucose, overweight (BMI } \geq 25) \text { or obese } \\
\text { patients and patients with diabetes, hypertension, a family history of diabetes, or high cholesterol were excluded. For Pap smear, patients with } \\
\text { a personal or family history of cancer of the cervix, or simply "uterus", were excluded. For gynecological ultrasound, patients with a personal } \\
\text { or family history of ovarian, breast, uterine, or vulvae cancers were excluded. For breast ultrasound and mammography, patients with a } \\
\text { personal or family history of breast or ovarian cancer were excluded. For lung X-ray, patients with a personal or family history of lung cancer } \\
\text { were excluded. For evaluation of PSA and prostate ultrasound, patients with a personal or family history of prostate cancer were excluded. For } \\
\text { the fecal occult blood test (FOBT), patients with a personal or family history of colon or rectal cancer were excluded. For abdominal } \\
\text { ultrasound, patients with a personal or family history of liver or pancreatic cancer were excluded. For thyroid ultrasound, patients with a } \\
\text { personal or family history of thyroid cancer were excluded. }\end{array}$} \\
\hline
\end{tabular}


Mean of the degree of importance that individuals attribute to medical activities on a scale of 1 to 10

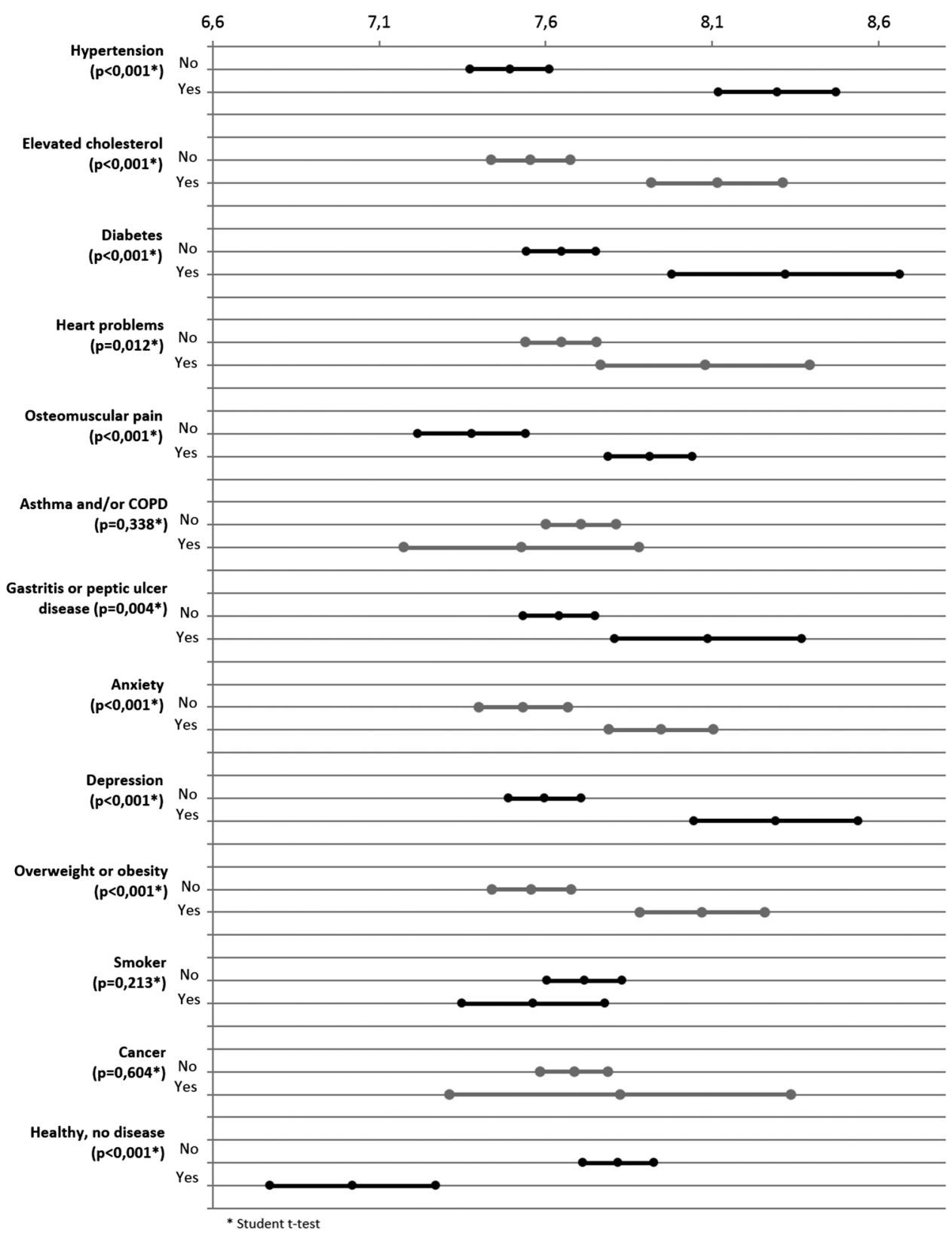

Figure 1 Factors influencing the level of importance attributed to medical activities. COPD, chronic obstructive pulmonary disease.

medical activities. The female respondents $(\mathrm{p}<0.001)$, the 40-79-year age group $(\mathrm{p}<0.001)$, the respondents with body mass indices (BMIs) $\geq 30(\mathrm{p}=0.002)$ and the respondents with a basic level of education $(\mathrm{p}<0.001)$ reported significantly higher importance scores for the medical activities. Students $(\mathrm{p}<0.001)$ and those respondents who had private health insurance $(p<0.001)$ gave lower importance scores for the medical tests. Regarding the self-reported health status, respondents claiming reasonable and weak health statuses reported significantly higher importance scores for the medical tests/interventions than those claiming a good-to-optimal health status $(p<0.001)$. There were no statistically significant differences between the rural and urban respondents.
In figure 2, we analyse the level of importance attributed to the different medical activities after accounting for self-reported health problems. Having a health problem significantly increases the importance attributed to tests $(7.82$ vs $6.96, \mathrm{p}<0.001)$; the opposite happens if the responder considers himself healthy $(p<0.001)$. Almost all conditions were significantly associated with greater importance attributed to medical activities except asthma and/or COPD, smoking and cancer.

\section{DISCUSSION}

These results show that the adult Portuguese population considers different medical preventive activities very important, similar to previous studies in other countries. ${ }^{1} 791018$ 
Mean of the degree of importance that individuals attribute to medical activities on a scale of 1 to 10

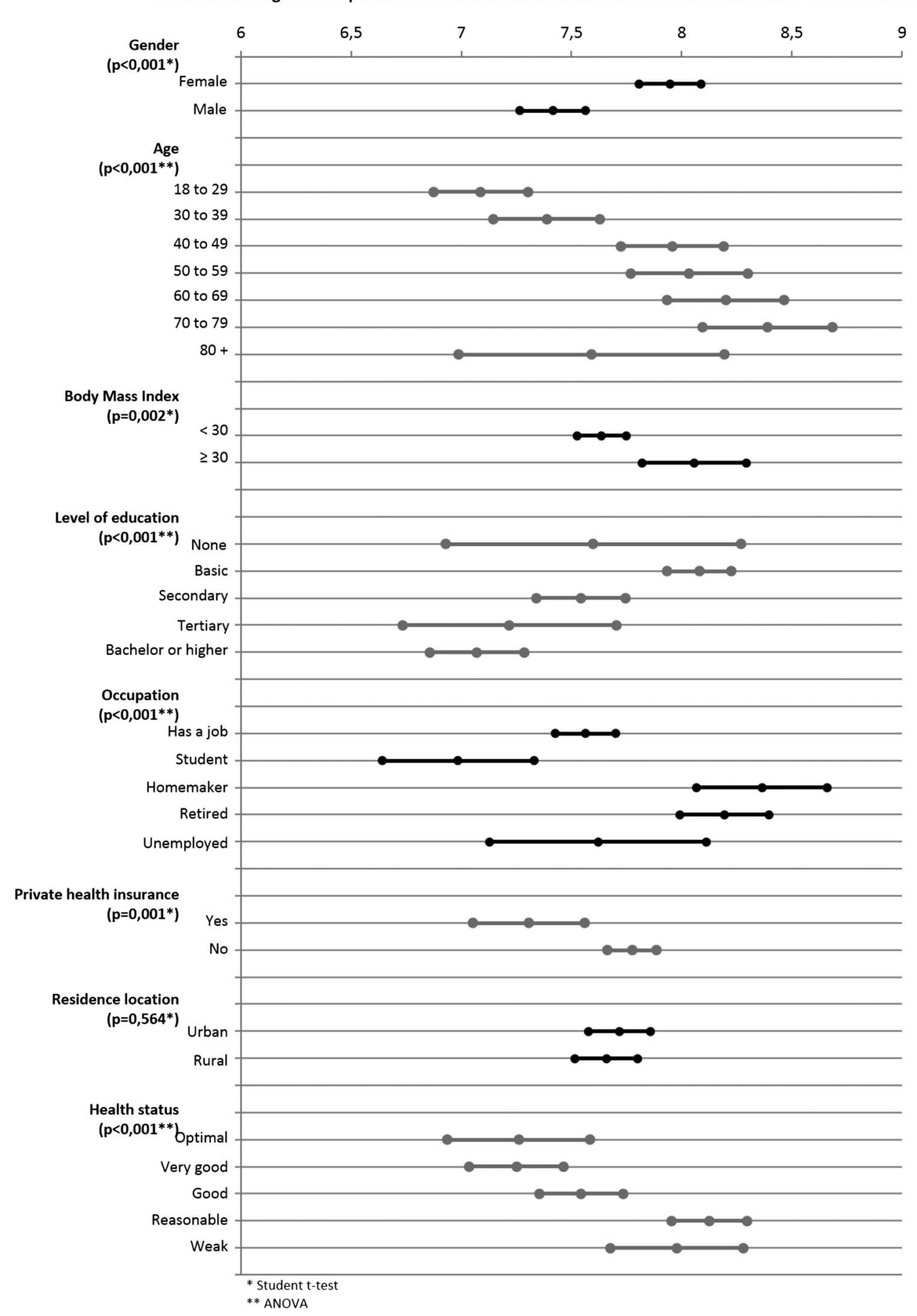

Figure 2 Medical conditions influencing the level of importance attributed to medical activities. ANOVA, analysis of variance.

In our study, the importance given to preventive activities was very similar between the groups with or without conditions or risk factors; therefore, preventive activities are equally important for all. When analysing by selfreported illness, we found that having any disease increases the importance attached to all preventive medical activities except for the smokers and patients with respiratory disease or cancer. It seems that the Portuguese are not aware of the individualisation of risk, have difficulty recognising risk factors and are unaware that not all preventive activities are suited to their situation.
The medical activity to which the respondents attributed the most importance is 'routine blood and urine tests'. This test is very popular among the Portuguese in periodic health examinations or routine health checks. In Portugal, there are no official recommendations for the frequency of adult periodic health examinations, including routine blood tests, but our previous study showed that $99.2 \%$ of Portuguese adults believed they should undergo general routine blood and urine tests, with a mean frequency interval of 12 months; $87.4 \%$ reported that they usually underwent this activity. ${ }^{2}$ The 
patients' perceived need for yearly routine blood and urine tests may be linked to the traditional concept of an annual periodic health examination and seems to be strongly and more culturally rooted in the Portuguese population, ${ }^{2}$ but there is little evidence that such visits actually provide some benefit for healthy adults. ${ }^{19-22}$

The Portuguese Ministry of Health recommends the following three cancer screenings: breast cancer screening by mammography every 2 years, for women from 50 to 69 years old; colorectal cancer screening by FOBT every 1 to 2 years, for adults from 50 to 74 years old; and cervical cancer screening with Pap smears for women between 25 and 60 years old, every 3 years following two annual normal tests. ${ }^{23}$

Our results reveal that the Portuguese are very aware and consider cancer screening very important, similar to other studies. ${ }^{791018}$ This may be due to the National Cancer Plan, established in Portugal in 1990, with great involvement of FPs and direct-to-consumer marketing, specifically national public health campaigns on screening.

Our patients, however, did not discriminate between medical tests that were important due to evidence-based recommendations and those that were not. For example, they attributed similar importance to Pap smears and gynaecological ultrasound scan as to breast ultrasound scan and mammography. Our previous study showed that the majority of Portuguese women considered these four tests on a nearly annual basis. ${ }^{2}$ This false idea is the result of the strong message from the massive campaigns women have received for decades that they must have early screening and early detection to increase the likelihood of curing cancer. Physicians, FPs included, also perpetuated this idea after perhaps being encouraged to recommend screening and preventive interventions to their patients by professional guidelines and expert opinions. ${ }^{1}$

Interestingly, men attribute less importance to malespecific interventions than woman to female-specific interventions, possibly due to lower exposure to such screenings in primary care, having fewer screening tests and being less familiar with healthcare. Portuguese women use more health resources than men. ${ }^{24}$ Men, however, attribute the same importance to prostate ultrasound scan and evaluation of PSA possibly due to strong advertising campaigns in the past that promised effective prostate cancer screenings, despite the fact that prostate cancer screening has never been officially proposed in Portugal.

Unsurprisingly, colorectal cancer screening is not considered as important for screening as other cancers. Colorectal cancer screening by FOBT was the last cancer screen to enter the Portuguese National Cancer Plan and it has not been promoted the same way as other cancer screening programmes. Intervention efforts should be made to effectively disseminate knowledge regarding the benefits of this screening, ${ }^{25}$ because colorectal carcinoma is the leading cause of cancer in Portugal. ${ }^{23}$ Our previous study showed that only $16.7 \%$ of the Portuguese population are screened by FOBT. ${ }^{2}$
Our results also show that patients' importance scores for medical testing are far from what the scientific evidence recommends. Note the importance attribute to lung X-ray and abdominal and thyroid ultrasound scans, even in the absence of risk factors. We believe that the importance attached to these tests is related to the respondent's belief of early detection of cancers.

Portuguese patients attributed great importance to tests related to cardiovascular risk factors (dyslipidaemia, diabetes and hypertension), which increased if they had conditions or risk factors. This may be because Portuguese primary care is well organised regarding the follow-up of diabetes and hypertension. Our findings of overestimation of the benefits of cardiovascular disease prevention are consistent with previous studies of perceptions of the benefits of lipid lowering and hypertension treatment. ${ }^{1}$ Cardiovascular diseases are the primary cause of death in Portugal. ${ }^{23} 26$

Our study suggests that the Portuguese consider diagnostic and laboratory tests much more important than the interventions of preventive counselling and health promotion. They attribute lower importance to lifestyle measures, such as advice regarding healthy eating, weight and alcohol and tobacco consumption. These results run counter to the European trend revealed in the EUROPREVIEW study that shows that patients consider changes in lifestyle important or very important to health improvement. ${ }^{10}$ The Portuguese seem unaware that behavioural risks are the main modifiable risk factor for the prevention of chronic conditions ${ }^{27}$ and counselling is not seen as a 'true' medical prescription. Another explanation could be that patients are not as often reminded of important lifestyle-related risk factors as they should be and, thus, are unaware of their unhealthy lifestyles. ${ }^{10} 2829$ Others think that many patients take risks not because of ignorance but after weighing the rewards against the risks; when clinicians counsel patients about any behaviour risk, the patients' receptivity can depend on their readiness to change. ${ }^{10}$ The Health Belief Model suggests that adherence to preventive counselling depends on perceived susceptibility, perceived severity, perceived benefits and perceived barriers. ${ }^{30}$

The Portuguese seem aware of the importance of unhealthy eating and their weight, but further efforts are required to educate the public about the risks associated with alcohol consumption and smoking. Some studies show that alcohol drinkers do not see or fail to admit that alcohol use is a risky habit that needs to be changed. $^{8} 10$

Socioeconomic factors and health status influence the levels of importance attributed to medical activities. Women in the 40 to 79-year-old age group, the obese, those with a basic level of education, homemakers/retirees, those without private health insurance, those with reasonable or weak health status and participants with medical conditions all placed a higher level of importance on preventive services. Other studies show that 
lower levels of education, increased age and previous screening or disease experience were associated with higher estimations of the benefits of interventions. ${ }^{10}$ It would be interesting to observe whether these findings are replicated in other countries and to study the justification of these associations.

Why do Portuguese patients attribute such high levels of importance to medical tests and preventive services?

It is not clear why patients have overly optimistic expectations, but some researchers have pointed to deficiencies in the quality of information provided to patients. ${ }^{1} 7918$ For example, when physicians promote cancer screening, they tend to promote the benefits and say little about the harm; leaflets, posters and advertising media also tend to show only the benefits. In addition, we think that doctors do not assess their patients' perceptions of the harms associated with screening and medical interventions ${ }^{1}$ and patients are not curious about such harm. The notion of 'the more tests, the better' is very rooted in the Portuguese population, giving them the false sense that they are 'in good health'.

Doctors may also tend to overestimate the magnitude of the benefits of some preventive activities and have difficulty imparting numerical estimates of the benefits to the patient in the interpretation of screening test results, which may impair the ability to facilitate informed decision-making by their patients. ${ }^{1}{ }^{31}$ For example, in cancer screening, evidence shows that the harms are poorly reported in randomised trials, so healthcare practitioners cannot make informed choices about them. ${ }^{32}$ The belief that more care is better, a lack of knowledge of the harm from overuse, discomfort with uncertainty and regret for errors of omission or inaction ${ }^{33}$ could explain Portuguese FPs' excessive use of some medical interventions. $^{34}$

Given the potential for serious harm in healthy individuals, screening should be offered only when the benefits are firmly documented and considered to outweigh the harms, which should be equally well-quantified. ${ }^{32}$ The harm of overuse may include overdiagnosis with misclassification (false-positive or false-negative tests), incidental findings and complications from diagnostic investigations and subsequent overtreatment (physical, psychological and economic costs). ${ }^{33}$

It is possible that the use of decision aids may reduce patients' tendency to overestimate interventions benefits and, thus, improve their ability to make informed decisions to accept or decline interventions. ${ }^{1}$ FPs should be aware of the recommended testing for cardiovascular risk factors and cancer screening to better educate patients regarding the judicious use of such tests. ${ }^{10}$ The challenge now is to balance messages and reduce the public's risk for overuse, overdiagnosis and overtreatment, ${ }^{73}$ but this will take time in the consultation $^{6}$ and will be hard to communicate in the presence of such enthusiasm and consumerism. More research is needed to explore ways to convey this message.
Our study has some limitations. First, we obtained a $55 \%$ response rate, which may be considered low. Low response rates are a frequent limitation in this type of population survey and may constitute a source of selection bias. Changes in telecommunications, marketing and culture are some of the factors that are thought to contribute to the growing threat of non-responses to household telephone surveys. ${ }^{14} 35$

Second, we have to consider that we are dealing with a self-perceived assessment of the participant's medical condition that may not correspond to the true need for health services. Patients may have erroneous perceptions about their medical conditions and this may also interfere with the level of importance they attribute to medical services.

Third, the questionnaire focused on a limited set of medical tests/interventions. To include other medical tests, for example, more serum tumour markers or CT scans, would have been interesting. We did not include these tests because doing so would have excessively extended the duration of the interviews.

Fourth, to select a representative sample of the Portuguese adults, we implemented a stratified cluster sampling of households and randomly selected participants in each household based on birthdates. We implemented quotas, however, for age and gender strata for each geographical region. Thus, the quota-sampling scheme has inherent limitations.

Despite the limitations of our study, we believe that this optimistic scenario about medical preventive activities is generalisable to the Portuguese population, the vast majority of Western European countries and many other developed/developing countries in the world.

\section{CONCLUSIONS}

Our results reveal that Portuguese patients overestimate the importance of preventive medical activities, tend to give more importance to diagnostic and laboratory tests than to lifestyle measures, do not discriminate tests that are important and evidence-based and seem not be aware of the individualisation of risk.

Of particular note are the importance attributed to 'routine blood and urine tests' attached to the traditional periodic health examination or routine health checks, the high importance of the type of tests considered in cancer screening and the minimal importance attributed to alcohol and tobacco consumption. On the other hand, the Portuguese seem be very aware of dyslipidaemia, diabetes and hypertension.

These findings suggest that FPs should be aware of these optimistic expectations, because this can influence the doctor-patient relationship when discussing these interventions and incorporating personalised risk. Patients and physicians should receive accurate information on the benefits, harms and limitations of medical interventions to be able to participate in shared decision-making. Educating patients regarding 
appropriate expectations will require effort from health systems to adjust the patients' perceived importance of medical testing.

\section{Twitter Follow Carlos Martins at @mgfamiliarnet}

Contributors CM and LS developed the original idea for this study. CM, LS and LFA designed the questionnaire, the sampling methodology and drafted, and revised the paper. CM conducted the quality control during the data collection. CM, LS and OR planned, supervised and performed the statistical data analysis, contributed to the paper draft, and revised the paper. PS, LC, $\mathrm{AC}-\mathrm{P}$ and $\mathrm{AH}$ contributed to the questionnaire design and revised the paper.

Funding This research received no specific grant from any funding agency in the public, commercial or not-for-profit sectors.

Competing interests None declared.

Ethics approval São João Health Centre Medical Ethics Committee.

Provenance and peer review Not commissioned; externally peer reviewed.

Data sharing statement No additional data are available.

Open Access This is an Open Access article distributed in accordance with the Creative Commons Attribution Non Commercial (CC BY-NC 4.0) license, which permits others to distribute, remix, adapt, build upon this work noncommercially, and license their derivative works on different terms, provided the original work is properly cited and the use is non-commercial. See: http:// creativecommons.org/licenses/by-nc/4.0/

\section{REFERENCES}

1. Hudson B, Zarifeh A, Young L, et al. Patients' expectations of screening and preventive treatments. Ann Fam Med 2012;10:495-502.

2. Martins $\mathrm{C}$, Azevedo LF, Ribeiro O, et al. A population-based nationwide cross-sectional study on preventive health services utilization in Portugal-what services (and frequencies) are deemed necessary by patients? PLOS ONE 2013;8:e81256.

3. Gérvas J, Starfield B, Heath I. Is clinical prevention better than cure? Lancet 2008;372:1997-9.

4. Sackett DL. The arrogance of preventive medicine. CMAJ 2002;167:363-4.

5. Moynihan R, Doust J, Henry D. Preventing overdiagnosis: how to stop harming the healthy. BMJ 2012;344:e3502

6. Getz L, Sigurdsson JA, Hetlevik I. Is opportunistic disease prevention in the consultation ethically justifiable? BMJ 2003;327:498-500.

7. Schwartz LM, Woloshin S, Fowler FJ, et al. Enthusiasm for cancer screening in the United States. JAMA 2004;291:71-8.

8. Brenner H, Heywang-Köbrunner S, Becker N. Re: Public knowledge of benefits of breast and prostate cancer screening in Europe. J Natl Cancer Inst 2010;102:356; author reply 356-7.

9. Domenighetti G, D'Avanzo B, Egger M, et al. Women's perception of the benefits of mammography screening: population-based survey in four countries. Int J Epidemiol 2003;32:816-21.

10. Brotons C, Bulc M, Sammut MR, et al. Attitudes toward preventive services and lifestyle: the views of primary care patients in Europe. The EUROPREVIEW patient study. Fam Pract 2012;29(Suppl 1): i168-76.

11. Marshall KG. Prevention. How much harm? How much benefit? 1. Influence of reporting methods on perception of benefits. CMAJ 1996;154:1493-9.
12. Elwyn G. Arriving at the postmodern medical consultation. Eur J Gen Pract 2004;10:93-7.

13. Oboler SK, Prochazka AV, Gonzales R, et al. Public expectations and attitudes for annual physical examinations and testing. Ann Intern Med 2002;136:652-9.

14. Groves RM. Nonresponse rates and nonresponse bias in household surveys. Public Opin Q 2006;70:646-75. http://poq.oxfordjournals. org/content/70/5/646 (accessed 28 Jun 2015).

15. Groves R, Biemer P, Lyberg L, et al. Telephone survey methodology. New York: John Wiley and Sons, 1988.

16. Lohr S. Sampling: design and analysis. Pacific Grove, CA: Duxbury Press, 1999.

17. Statistics Portugal. National Statistical Institute, Census 2001. 2001. http://censos.ine.pt/ (accessed 28 Jun 2015).

18. Waller J, Osborne K, Wardle J. Enthusiasm for cancer screening in Great Britain: a general population survey. Br J Cancer 2015;112:562-6.

19. Ritual, Not Science, Keeps the Annual Physical Alive. 2015 April. http://www.medscape.com/viewarticle/842732 (accessed $19 \mathrm{Ju}$ 2015).

20. Gøtzsche PC, Jørgensen KJ, Krogsbøll LT. General health checks don't work. BMJ 2014;348:g3680.

21. Krogsbøll LT, Jørgensen KJ, Gøtzsche PC. General health checks in adults for reducing morbidity and mortality from disease. JAMA 2013;309:2489-90.

22. Sox HC. The health checkup: was it ever effective? Could it be effective? JAMA 2013;309:2496-7.

23. Health Portal-National Cancer Plan 2007-2010. http://www portaldasaude.pt/portal/conteudos/a+saude+em+portugal/ noticias/arquivo/2008/6/plano+oncologico.htm (accessed $18 \mathrm{Ju}$ 2015).

24. Entidade Reguladora da Saúde-Estudo do Acesso aos Cuidados de Saúde Primários-Relatório. http://www.sep.org.pt/files/2014/05/ 290514ERS.pdf (accessed 15 May 2016)

25. US Preventive Services Task Force. Colorectal Cancer: Screening 2008 October. http://www.uspreventiveservicestaskforce.org/Page/ Document/UpdateSummaryFinal/colorectal-cancer-screening (accessed 24 Sep 2015).

26. OECD. Health at a Glance: Europe 2014. http://www.oecd.org/ health/health-at-a-glance-europe-23056088.htm (accessed 24 Sep 2015).

27. WHO. Innovative care for chronic conditions: building blocks for action. 2002. http://www.who.int/diabetes/publications/icccreport/en/ (accessed 19 Jul 2015).

28. Little P, Slocock L, Griffin S, et al. Who is targeted for lifestyle advice? A cross-sectional survey in two general practices. $\mathrm{Br} J \mathrm{Gen}$ Pract 1999;49:806-10.

29. Silagy C, Muir J, Coulter A, et al. Cardiovascular risk and attitudes to lifestyle: what do patients think? BMJ 1993;306:1657-60.

30. Hespanhol AP, Couto L, Martins C. Preventive medicine. RPMGF 2008;24:49-64.

31. Sapre N, Mann S, Elley CR. Doctors' perceptions of the prognostic benefit of statins in patients who have had myocardial infarction. Intern Med J 2009;39:277-82.

32. Heleno B, Thomsen MF, Rodrigues DS, et al. Quantification of harms in cancer screening trials: literature review. BMJ 2013;347: f5334.

33. Morgan DJ, Brownlee S, Leppin AL, et al. Setting a research agenda for medical overuse. BMJ 2015;351:h4534.

34. Martins C, Azevedo LF, Santos C, et al. Preventive health services implemented by family physicians in Portugal-a cross-sectional study based on two clinical scenarios. BMJ Open 2014;4:e005162.

35. O'Toole J, Sinclair M, Leder K. Maximising response rates in household telephone surveys. BMC Med Res Methodol 2008;8:71. 